\title{
THEORETICAL STUDY ON THE EFFICIENCY OF UTILIZATION OF NANOCLAY-CFRP COMPOSITE MATERIALS IN THE ROOT AREA OF WIND TURBINE BLADES
}

\author{
Layth Al-Rukaibawi ${ }^{1,2}$, Miodrag J. Lukic \\ ${ }^{I}$ School of Civil Engineering and Geosciences, Newcastle University, \\ Newcastle Upon Tyne, NE17RU, UK \\ ${ }^{2}$ Department of Building and Construction Engineering, \\ University of Technology, Baghdad, 10066, Iraq \\ ${ }^{3}$ Institute of Technical Sciences of the Serbian Academy of Sciences and Arts, \\ Knez Mihailova 35/IV, Belgrade, Serbia
}

Received 16.10.2018

Accepted 11.12.2018

\begin{abstract}
In this study, theoretical calculations were performed to determine the most efficient utilization of nanoclays added as reinforcement for CFRP composite materials used for wind turbine blade manufacture. Four different V39 blade models were created, and numerical simulations by FEA were performed. Glass Fibre Reinforced Polymers (GFRP), whole model made of Carbon Fibre Reinforced Polymers/nanoclay (2\%) (CFRPN2), Hybrid Glass and Carbon/nanoclay (2\%) (HGCN2) and Hybrid Glass and Carbon/nanoclay (5\%) (HGCN5). The targeted part was the joining zone between the root and the blade. The most important finding to emerge from this study is that the modest addition of nanoclay (2\%) with carbon fiber reinforced polymer leads to a significant stiffer blade, with a minimal deflection, about $70 \%$ lower than GFRP. Furthermore, the HGCN2 model is considered to be safer as it has a lower stress concentration than others $\left(52.84 \mathrm{kN} / \mathrm{m}^{2}\right)$. It can be considered that the probability of failure of the entire root area will be decreased if nanoclay-CFRP hybrid blades are used, yielding higher durability and lower overall costs. These findings contribute to decisions related to materials selection, structural, aerodynamic design and layup schedule choice.
\end{abstract}

Keywords: CFRP-nanoclay; Hybridization; Joining zone; two-steps homogenyzation; ABAQUS

\footnotetext{
* Corresponding author: Layth Al-Rukaibawi, laythsalman30@gmail.com
} 


\section{Introduction}

The modern wind blades made of fibre-reinforced polymer composite materials are lightweight and have a high stiffness, excellent corrosion resistance and good ability to mitigate static and fatigue failures. Additionally, they have a lower cost than conventional fabrics [1]. Long glass and carbon fibres are usually used and provide a primary structural component of the wind blade composite materials [2], but despite high tensile strength, impact resistance, excellent chemical resistance and low cost [3], glass fibres do not meet the requirements of rotor size augmentation and blade length [4].

Addition of nano-sized agents in a polymeric matrix as a secondary reinforcement during synthesis of traditional carbon fibre-reinforced composites can provide the exceptional mechanical properties and multi-functional character of the composites [5]. Nanoclays are particularly interesting due to their excellent functional properties and low cost [6]. Recent developments in large rotor radius blades have increased the need for advanced composite materials with improved functional properties to withstand extreme wind loadings and weather conditions [2, 7]. Currently, a promising advancement is offered by polymer/nanoclay composites with fascinating mechanical properties gained by the addition of a modest amount of nano-fillers [8].

The influence of nanoclays addition to polymer matrix on mechanical properties of composites was previously investigated. The effect of nanoclay addition ( 2 to $4 \mathrm{phr}$ ) on mechanical properties of carbon fibre-reinforced tetraglycidyl diamino diphenylmethane (TGDDM) epoxy composite. The mode I interlaminar fracture toughness continuously increased for $85 \%$ with the increase of nanoclay content up to $4 \mathrm{phr}$ in an epoxy matrix, while flexural strength was improved by $38 \%$ with 2 phr of nanoclay [9]. Siddiqui et al. (2007) investigated the influence of I30.P organo-nanoclay $(0,3,5$, and 7 wt.\%) on mechanical properties of CFR epoxy matrix. The results showed that flexural modulus and quasi-static fracture toughness were significantly improved, for 26 and $60 \%$, respectively, with the addition of 3 wt. \% of nanoclay, while the further increase in concentration adversely affected mechanical behavior [10]. Karippal et al. (2011) investigated the mechanical properties of glass fibre-reinforced nanoclay/epoxy composites. The addition of Nanomer 1.30E nanoclay (0-6 wt.\%) LY556 epoxy resin increased ultimate tensile strength, Young's modulus, flexural strength and modulus, interlaminar shear strength and micro-hardness for 30, 38, 120, 25, 70 and 25\%, respectively, with nanoclay volume fraction up to $5 \mathrm{wt} . \%$ [11].

To the authors' best knowledge, investigation of mechanical properties of carbon fibre-reinforced nanocomposite with Cloisite $30 \mathrm{~B}$ nanoclay addition has not been previously reported. In this study, different blade models were created with following materials compositions: glass fiber-reinforced polymer (GFRP), carbon fiber-reinforced polymer/nanoclay (2\%) (CFRPN2), hybrid glass-carbon/nanoclay (2\%) (HGCN2) and hybrid glass-carbon/nanoclay (5\%) (HGCN5). Afterward, numerical simulations were performed. All blade models were utilized with different blade schedule. The HGCN models were entirely made of glass fibres except for the replacement of $0^{\circ}$ unidirectional glass fibres with 2 and 5\% of nanoclay synergized with carbon fibre-reinforced polymer at the root area. The mathematical homogenization approach in two steps (Mori - Tanaka and Voigt -Reuss) has been employed to find an effective homogeneous material (micro-level), which has the same effective macro-stiffness as a real heterogeneous composite under the same boundary conditions. Afterward, the CAD model of wind 
turbine blade based on the NREL aerofoil family was created using SolidWorks. Further, the rotor blade models were imported into ABAQUS and all composite blade models were simulated using the finite element analysis (FEA). The four models were imposed on bending loadings and rotational forces due to the radial movement of the blade. The findings of these numerical simulations give an invaluable insight into the appropriate extent of nanoclay addition to CFRP composites regarding the strength, stiffness, and durability.

\section{Experimental}

\section{Two-step homogenization approach}

The fundamental concept of homogenization in linear elasticity is intended to find an effective homogeneous material (micro-scale) that has the same effective stiffness for macro-scale as a real heterogeneous composite under the same boundary conditions [12]. The objective of the extent of analytical homogenization is to calculate the volume averages of stress and strain fields at the macro-scale and in every phase accurately.

Multiphase composites materials in the present work consist of a matrix polymer and two inclusion phases (particles and fibres). The two-step homogenization of such composites is carried out and can be performed as it is very general for all material models and not restricted to misaligned inclusions, Fig. 1. Choosing the inclusion family at each level has an impact on the final predictions. It is essential to choose the stronger inclusion type at the final level of homogenization as it influences the final predictions. Thus, herein the inclusions were chosen from the most compliant (particles) to the most rigid (fibres).

The two-step homogenization is depicted and illustrated as follows: first, at the deepest level (2), the real matrix polymer is homogenized with a first family of nanoclay inclusions (black) by the Mori-Tanaka model. Afterward, the effective response or overall properties is computed. In the second step, imaginary new matrix (grey) is reinforced with carbon fibres inclusions to constitute an upper level (1) nanocomposite by using the Voigt and Reuss schemes.

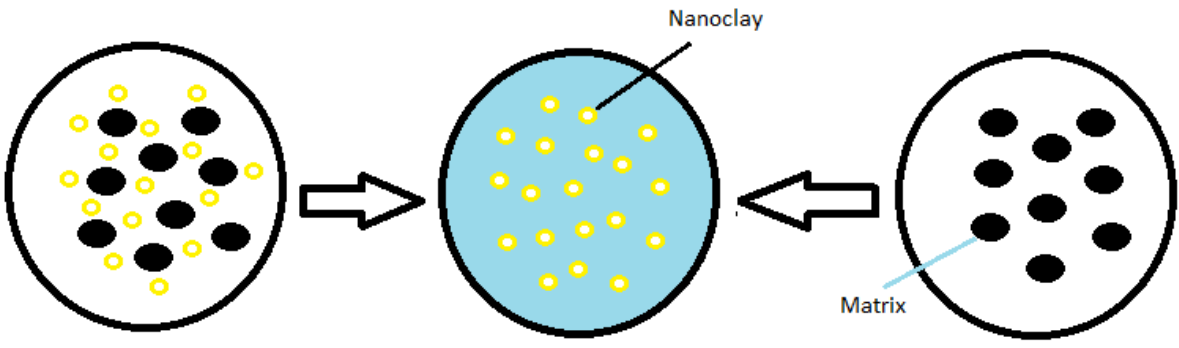

Heterogeneous material: 3 phases

Level 1

Level 2

Fig. 1. The two-step homogenization approach. 
Consequently, the macro-stiffness is found to be a volume average of the micro stiffness. In the Reuss model, the stress field is assumed to be uniform in the RVE. Therefore, the macro-compliance (the inverse of the stiffness) is found to be a volume average of the micro- compliances. However, the Voigt and Reuss models are too simplistic and assuming that strains or stresses are uniform within a composite is not realistic. It can now be summarised the properties of the elastic moduli of epoxy resin, carbon fibres and nanoclay used in this study in Table. 1 below.

Table 1. The elastic moduli of epoxy resin, carbon fibres, glass fibers and nanoclay used in this study.

\begin{tabular}{lcccc}
\hline Property & $\begin{array}{c}\text { Epoxy resin } \\
{[13]}\end{array}$ & $\begin{array}{c}\text { Glass fibres } \\
{[13]}\end{array}$ & $\begin{array}{c}\text { Carbon fibres } \\
{[14]}\end{array}$ & $\begin{array}{c}\text { Nanoclay } \\
{[15]}\end{array}$ \\
\hline $\mathrm{E}_{h}$, elastic modulus $(\mathrm{GPa})$ & 2.05 & 72 & 276 & 4.657 \\
$V$, Poisson ratio & 0.35 & 0.26 & 0.37 & 0.36 \\
G, shear modulus $(\mathrm{GPa})$ & 0.76 & 30 & 100 & 1.71 \\
Tensile strength $(\mathrm{MPa})$ & 68 & 2500 & 3000 & 101 \\
Density $\left(\mathrm{g} / \mathrm{cm}^{3}\right)$ & 1.2 & 2.5 & 1.8 & 1.98 \\
\hline
\end{tabular}

Moreover, if each phase is isotropic, both models predict isotropic composite regardless of the shape and orientation of the inclusions, which is physically untrue.

\section{Analytical homogenization for heterogeneous materials}

Step I: homogenizing matrix and filler

Firstly, the epoxy and nano fillers should be homogenized into an equivalent, smeared matrix material. This performed by the Mori-Tanaka method based on the Eshelby stress tensor. This method can be used to calculate the effective material properties of a composite [16]. For a composite with fillers having a low aspect ratio (i.e., spheres), the equations are given as follows:

$$
E_{h}=E_{m}+\frac{\phi_{p}\left(E_{p}-E_{m}\right)}{1+\left(1-\phi_{p}\right) \frac{E_{p}-E_{m}}{E_{m}+\frac{4 G_{m}}{3}}}
$$

where $\phi_{\mathrm{p}}$ is the particle volume fraction, $E m$ and $E p$ are elastic moduli of the matrix and particles, respectively, $\mathrm{Gm}$ is the shear modulus of the matrix, and $E_{h}$ is the homogenized elastic modulus of the epoxy-particle mixture. Using the above equation, the effective elastic moduli of CFRPN2 and CFRPN5 are 2.06 and $2.08 \mathrm{GPa}$, respectively. Because of the relatively small amount of added filler, the Poisson's ratio is assumed to be mostly unchanged, and its value for the reinforced epoxy is taken as that of un-reinforced epoxy, or 0.36 .

$$
G_{h}=G_{m}+\frac{\phi_{p}\left(G_{p}-G_{m}\right)}{1+\left(1-\phi_{p}\right) \frac{G_{p}-G_{m}}{G_{m}+\frac{G_{m}\left(9 E_{m}+8 G_{m}\right)}{6\left(E_{m}+2 G_{m}\right)}}}
$$

where $G p$ is the shear modulus of the particles and $G h$ is homogenized shear modulus. The effective shear moduli of CFRPN2 and CFRPN5 are 0.76 and $0.78 \mathrm{GPa}$, 
respectively. It should be noted that nanoparticles (depending on material type) may significantly influence other properties of the composite, such as fracture toughness, hardness, thermal conductivity, which cannot be predicted by the previous analysis. The properties of the nano-filler-reinforced epoxy composites are shown in Table 2.

Table 2. The summarized elastic properties of the nano-filler reinforced composites.

\section{Property CFRPN2 CFRPN5}

\begin{tabular}{lcc}
\hline$E_{\mathrm{h}}(\mathrm{GPa})$ & 2.062 & 2.08 \\
$v_{h}$ & 0.36 & 0.36 \\
$G_{h}(\mathrm{GPa})$ & 0.76 & 0.78 \\
\hline
\end{tabular}

\section{Step II: Adding fiber reinforcement}

For a description of adding fibre reinforcements, the Halphin-Tsai equations can be used as follows:

$$
\begin{aligned}
& E_{1}=E_{f} V_{f}+E_{h}\left(1-V_{f}\right) \\
& E_{2}=\frac{\left(1+\frac{E_{f}-E_{h}}{E_{f}+E_{h}} V_{f}\right)}{\left(1-\frac{E_{f}-E_{h}}{E_{f}+E_{h}} V_{f}\right)} E_{m} \\
& G_{12}=\frac{\left(1+\frac{G_{f}-G_{h}}{G_{f}+G_{h}} V_{f}\right)}{\left(1-\frac{G_{f}-G_{h}}{G_{f}+G_{h}} V_{f}\right)} G_{m} \\
& v_{12}=v_{f} V_{f}+v_{m}\left(1-V_{f}\right)
\end{aligned}
$$

where subscript $f$ refers to fibre properties and subscript $h$ refers to homogenized particle/matrix properties as calculated previously. The engineering constants are the tangential moduli; $E_{1}$ represents the elastic modulus in the fibre direction, $E_{2}$ represents the elastic modulus in the transverse direction, $E_{3}$ represents the elastic modulus in the out-of-plane direction, the Poisson's ratios; $v_{12}$ the Poisson's ratio in the fibre direction, $v_{13}$ the Poisson's ratio in the transverse direction, $v_{23}$ the Poisson ratio in the out-of-plane direction, and the shear moduli; $G_{12}$ the shear modulus in the fibre direction, $G_{13}$ the shear modulus in the transverse direction, $G_{23}$ the shear modulus in the out-of-plane direction. $V_{f}$ is the fibre volume fraction. The fibre volume fraction for carbon and glass are taken as 0.58 and 0.55 , respectively. formula:

While the calculation for the density values are computed based on the following

$$
\rho_{c}=\rho_{f} V_{f}+\rho_{m}\left(V_{m}\right)
$$


where $\rho_{m}$ is the density of particles, and $\rho_{m}$ is the matrix density, respectively. Using the above equations, the following material properties are predicted for glass and carbon fibre systems and are shown in Table 3.

Table 3. The elastic properties of GFRP and CFRP-Clay composites.

\begin{tabular}{cccc}
\hline Property & GFRP & CFRPN2 & CFRPN5 \\
\hline$E_{1}(\mathrm{GPa})$ & 40.522 & 160.94 & 160.95 \\
$E_{2}(\mathrm{GPa})$ & 4.066 & 4.859 & 4.901 \\
$E_{3}(\mathrm{GPa})$ & 4.066 & 4.859 & 4.901 \\
$\nu_{12}$ & 0.30 & 0.361 & 0.36 \\
$\nu_{13}$ & 0.30 & 0.361 & 0.36 \\
$\nu_{23}$ & 0.50 & 0.501 & 0.501 \\
$G_{12}(\mathrm{GPa})$ & 2.43 & 2.799 & 2.823 \\
$G_{13}(\mathrm{GPa})$ & 2.43 & 2.799 & 2.823 \\
$G_{23}(\mathrm{GPa})$ & 1.942 & 2.303 & 2.323 \\
$\rho(\mathrm{kg} / \mathrm{m} 3)$ & 1915 & 1552.2 & 1556.4 \\
\hline
\end{tabular}

\section{CAD design (Solidworks 2013)}

The blade design is based on the NREL Aerofoil S-series family for $400 \mathrm{~kW}$ large wind turbine blade (S815-S814-S812-S813), as presented in Table 4.

Table 4. NREL aerofoils for blade design [17].

\begin{tabular}{lccclll}
\hline $\begin{array}{l}\text { Blade length } \\
(\mathrm{m})\end{array}$ & $\begin{array}{c}\text { Generator } \\
(\mathrm{kW})\end{array}$ & $\begin{array}{c}\text { Thickness } \\
\text { category }\end{array}$ & \multicolumn{4}{c}{ Aerofoil family (root tip) } \\
\cline { 1 - 5 } $10-15$ & $150-400$ & Thick & S815 & S814 & S812 & S813 \\
\hline
\end{tabular}

The length of the blade was $12.8 \mathrm{~m}$. Aerofoil transitions were taken as shown in Table 5, where $\mathrm{X}$ is the local length of the blade along the span, and $\mathrm{R}$ is the total length of the blade.

By considering the chord length, thickness and twist angle distributions, the aerofoils are distributed along the blade to extract power as high as possible.

Table 5. The NREL aerofoils distribution for wind blade design.

\begin{tabular}{lcccc}
\hline $\mathrm{X}(\mathrm{m})$ & $\mathrm{X} / \mathrm{R}$ & Twist angle (deg.) & Chord length $(\mathrm{m})$ & Aerofoils, distribution \\
\hline 0 & 0 & 0 & 0 & Circle \\
3.2 & 0.200 & 0 & 1.900 & $\mathrm{~S} 815$ \\
4 & 0.250 & 8.23 & 1.734 & $\mathrm{~S} 815$ \\
4.8 & 0.299 & 16.47 & 1.567 & $\mathrm{~S} 815$ \\
5.6 & 0.351 & 24.20 & 1.409 & $\mathrm{~S} 814$ \\
6.4 & 0.403 & 30.69 & 1.268 & $\mathrm{~S} 814$
\end{tabular}




$\begin{array}{lllll}7.2 & 0.450 & 36.67 & 1.118 & \mathrm{~S} 812 \\ 8 & 0.500 & 40.91 & 1.001 & \mathrm{~S} 812 \\ 8.8 & 0.552 & 43.89 & 0.884 & \mathrm{~S} 812 \\ 9.6 & 0.601 & 44.87 & 0.784 & \mathrm{~S} 812 \\ 10.4 & 0.651 & 45.11 & 0.692 & \mathrm{~S} 812 \\ 11.2 & 0.700 & 45.09 & 0.601 & \mathrm{~S} 812 \\ 12 & 0.750 & 45.08 & 0.525 & \mathrm{~S} 812 \\ 12.8 & 0.802 & 45.06 & 0.442 & \mathrm{~S} 813\end{array}$

\section{CAD implementation}

The blade was modeled in SolidWorks 2013 with 13 aerofoils cross-section profiles and circular section being located at the origin point. The aerofoils files that include the points in a coordinate system $(\mathrm{x}, \mathrm{y}, \mathrm{z})$ and their locations, were imported into SolidWorks as curves (Fig. 2, and Fig. 3).

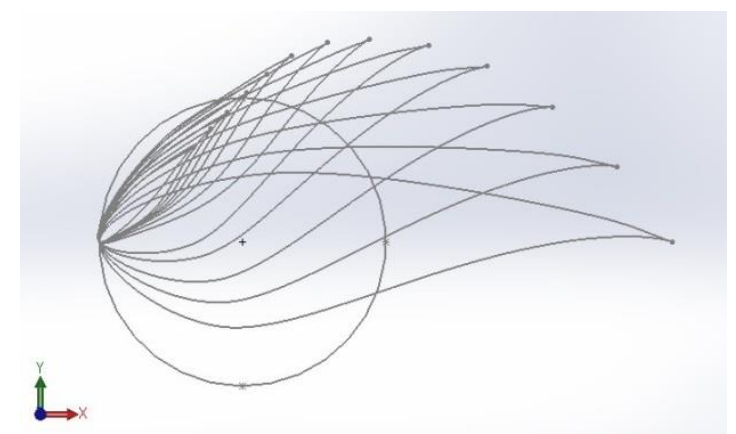

Fig. 2. The NREL aerofoils: cross-sectional front view.

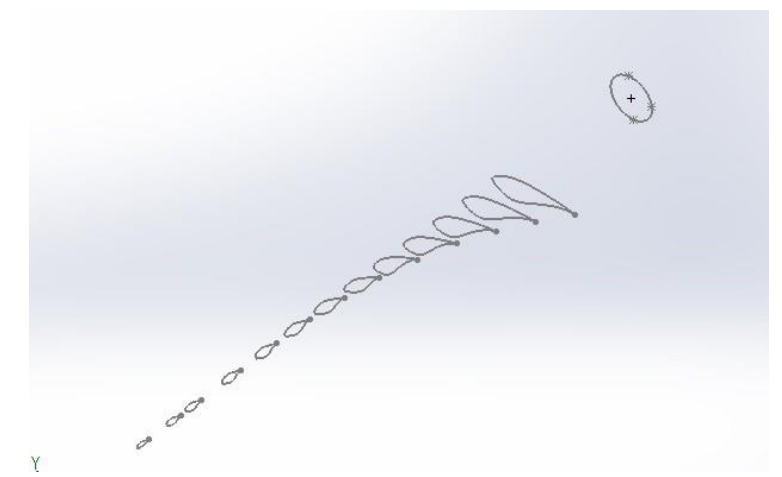

Fig. 3. The NREL aerofoils distributions: isometric view.

The spar caps and shear webs were modeled at 15 and 50\% along the chord length of each aerofoil except near the root where the circular section was used. 
Afterward, the final step is to use the shell loft feature in SolidWorks to provide a smooth surface of blade geometry. For this feature, it was challenging to select the right points to start from these aerofoils and to be done successfully (Fig. 4).

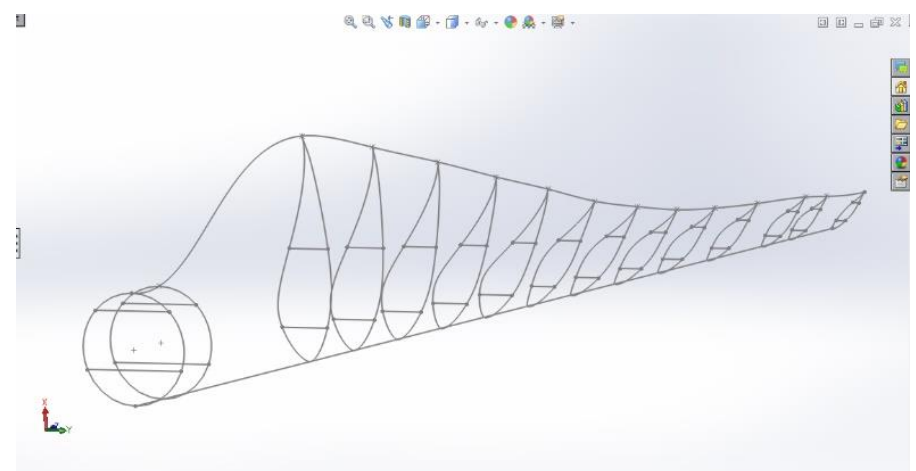

Fig. 4. The NREL aerofoil distributions: isometric view.

\section{FEA Pre-processing using ABAQUS}

Importing the SolidWorks model

When the working assembly of the blade structure using the CAD software is created, the model was imported into ABAQUS. Since Abaqus/CAE does not have units so that the length of the blade was 12.8 meters and scaled by multiplying all lengths by 1 . This model is $400 \mathrm{~kW}$ wind turbine blade with the shear webs, Fig. 5 .

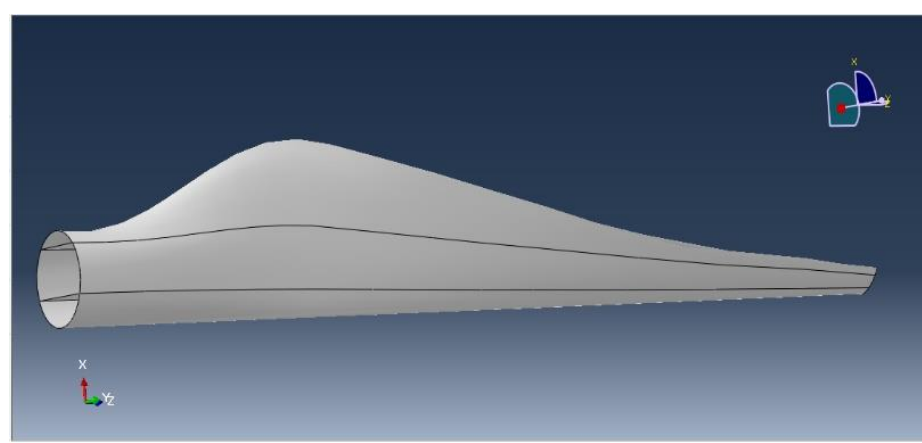

Fig. 5. The finalized rotor blade in ABAQUS.

Partitioning the model

The blade was partitioned into 15 sections along the length for finite element preprocessing by using a datum surface, Fig. 6 . It is worth mentioning that a large number of sections permitted for a well-defined distribution of composite plies and aerodynamic point loads [18]. 


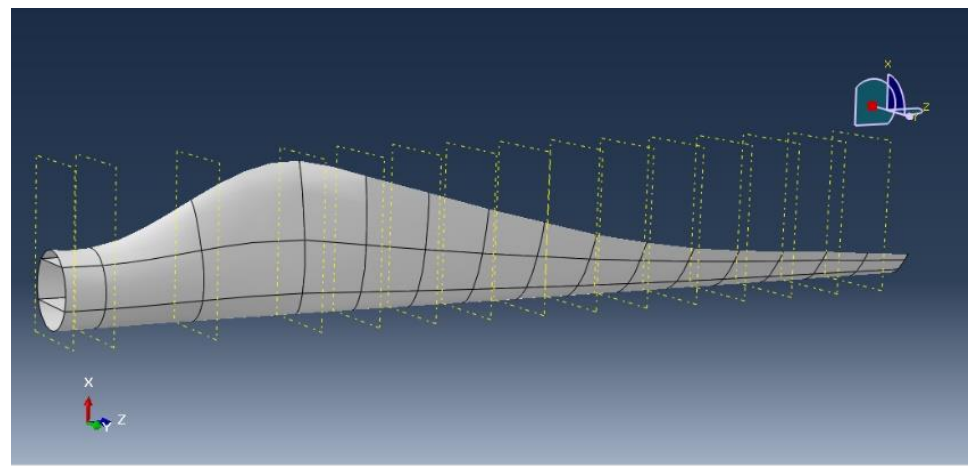

Fig. 6. The partitioning of the rotor blade using datum surfaces.

\section{Material properties and composite layups}

Besides from E-glass fibre/epoxy composites widely used as a solution to provide the stiffness, low weight and high fatigue life of large rotor blades, a possible solution of enhancing composite materials can be achieved by toughening the polymer matrix with nanomaterial at the range of (1-10 wt.\%) [19].

Composite layups in ABAQUS/CAE are capable of managing a sufficient number of plies in a typical composite model. The composite layups were defined using the ABAQUS/CAE composite layup editor that permits to assign the name of materials, ply orientation, ply thickness and regions on the partitioned geometry. There are two different layup sequences proposed and used, [0/45/-45] and [0/45/90/-45], based on the design-guidelines of composite laminate [20]. A composite layup [0/45/-45] contains three plies; each ply is composed of a heterogeneous material of a uniform thickness of $0.5 \mathrm{~m}$, with fibre typically oriented to $0^{\circ},+45^{\circ}$, and $-45^{\circ}$ orientations. The regions for each ply have been assigned on the partitioned geometry of wind blades. It can be noted, from the perspective of a manufacturer, that the $0 / \pm 45^{\circ}$ ply layup is the most practical solution used, while a quasi-isotropic layup [0/45/90/-45] has the advantage to withstand axial, transverse and shear loadings [18, 20].

The plies with $0^{\circ}$ orientation were placed alongside the blade length regarding making the blade capable of withstanding bending or axial loadings, while $\pm 45^{\circ}$ plies make it able to resist torsional stiffness and buckling, or shear loadings, while $90^{\circ}$ orientations carry the transverse loadings.

Primarily, the internal structure of the blade turbine was composed of spar caps in flap-wise direction joined by shear webs with the shell surfaces running along the length of the blade. The regions of spar caps were reinforced with unidirectional fibres at $0^{\circ}$ orientation to provide bending strength and react on bending loads which result from the aerodynamic lift forces acting on the flap wise direction and the blade selfweight on the edge direction. The shear webs were composed of diagonal fibres with $\pm 45^{\circ}$ orientation and joint with spar caps to transfer shear loads and resist buckling [21]. The outer shell surfaces should provide the blade with the torsional stiffness and slow down the crack propagation [4].

The spar caps region is considered as the most crucial region that carries almost $90 \%$ of the load [22]. It was formed by stacking piles of unidirectional fibres (glass or carbon) to achieve bending rigidity of the composite [18]. The shell also contributes to 
the torsional resistance of the blade [22]. Consequently, the shells have a diagonal orientation $\pm 45^{\circ}$ and symmetric layups [18]. The shells also have fibres running along the length of the blade in order to assist the spar caps during flap-wise bending load, as well as give the blade more strength in edgewise bending and reduce stress concentrations due to ply drops in the thin skin [18]. As shells are significantly more full than the spar, they are considered to be the most efficient to provide the edgewise bending stiffness.

In the present work, the Vestas V39 wind turbine blade with a length of $12.8 \mathrm{~m}$ is considered. The thickness of the blade increases towards the root in order to take the structural loads, in particular, the bending moments (see Appendix A - Table A.1 for the layup schedule and the thickness of laminate of the blade as well as the ply thickness of $0.5 \mathrm{~mm}$ ).

In order to check the utilization efficiency of CFRP with the addition of nanoclay in developing the parts near root areas of the blade, specifically at the joining zone between the blade and the root, Fig. 7, four models were investigated: GFRP, CFRPN2, HGCN2, and HGCN5.

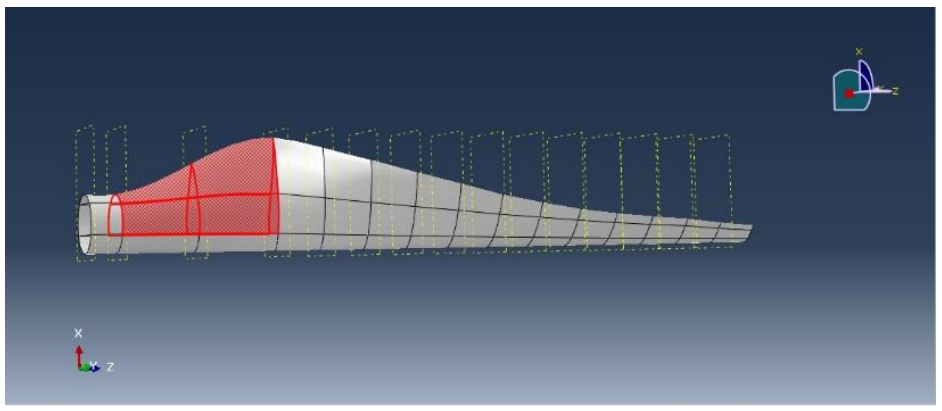

Fig. 7. HGCN2 and HGCN5 replacements near the root area of the blade.

For the HGCN2 and HGCN5, the unidirectional $0^{\circ}$ glass fibre plies, located in the center of the layup of different areas, were replaced by CN2 and CN5 respectively, while the $0^{\circ}$ at the outer surfaces and $\pm 45^{\circ}$ ply layups were not changed. [23] indicated that for hybrid composites placing glass fabric layers in the exterior and carbon fabric layers in the interior, gives a higher tensile strength and ultimate tensile strain compares to the opposite distribution. From a manufacturing point of view, $0^{\circ}$ ply of carbon fibres is more convenient than $\pm 45^{\circ}$, and the cost of manufacture is lower [4] (see Appendix A -Table A.2 for the different layup sequence used for the replacement of HGCN2, and HGCN5).

\section{Boundary conditions}

At root end of the blade, the connection to the hub was assumed to be rigid, relative to the blade. In order to create a boundary condition, the Create Boundary Condition button was used. Afterwards the Mechanical Category was selected and Symmetry/Antisymmetry/Encastre were chosen. As a consequence, the root of the blade is fixed, Fig. 8. 


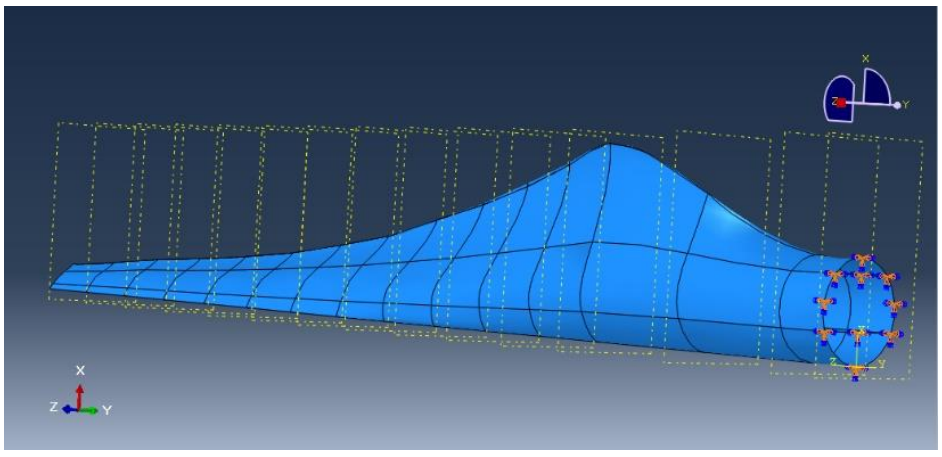

Fig. 8. The visual representation of the fixed root area.

\section{Mesh generation}

The parts of wind blade are plate-like, thin shell structures, and ABAQUS provides a wide range of different shell elements. If the shell elements in the analysis experience are bending, it is recommended to use curved shell elements. Therefore, the blade model was meshed using the S4R element: a 4-node, doubly curved element with reduced integration and hourglass control, appropriate for thick or thin shell applications. The visual representation of the meshed blade design is depicted in Fig. 9.

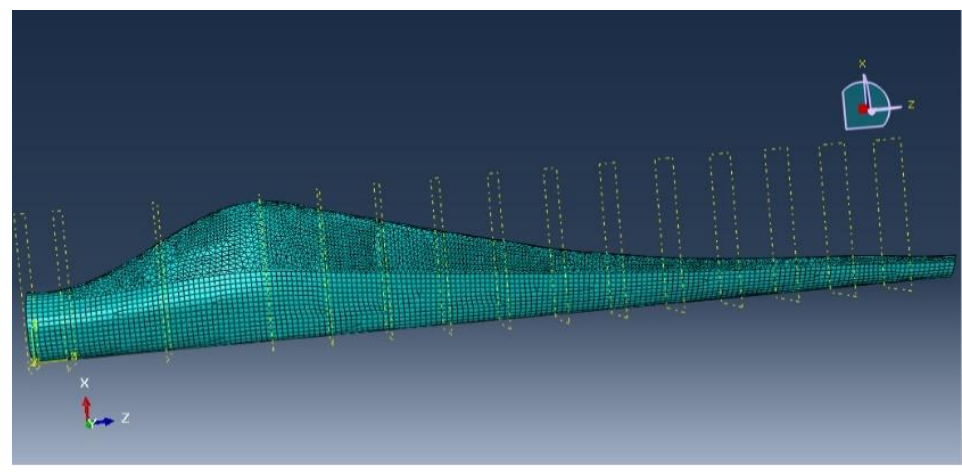

Fig. 9. The visual representation of the meshed blade design.

\section{Load arrangements and load cases}

Wind turbines are installed in areas that have relatively consistent and strong winds [24]. The wind loading is a significant design criterion of a wind turbine system. The energetic or decisive standard about the load assumptions of a wind turbine is the International Electrotechnical Commission [25, 26].

This standard is considered for wind load calculations based on the design class of the wind turbine generator system (WTGS) [26], Table.6. It appears that "Class I" is designated for severe loading condition with the annual average wind speed (Vave) of $10 \mathrm{~m} / \mathrm{s}$ and 50-year extreme wind of $70 \mathrm{~m} / \mathrm{s}$. Also, the characteristic value of the assuming turbulence intensity at $15 \mathrm{~m} / \mathrm{s}$ (I15) is $18 \%$. 
Table 6: Basic parameters for WTGS classes [26].

\begin{tabular}{lcccc}
\hline WTGS Class & I & II & III & IV \\
\hline$V_{\text {ref }}(\mathrm{m} / \mathrm{s})$ & 50 yr. & $42.5 \mathrm{yr}$. & $37.5 \mathrm{yr}$. & $30 \mathrm{yr}$. \\
$V_{\text {ave }}(\mathrm{m} / \mathrm{s})$ & 10 & 8.5 & 7.5 & 6 \\
$\mathrm{~A}, I_{15}(-)$ & 0.18 & 0.18 & 0.18 & 0.18
\end{tabular}

The primary load case used for developing structural designs was a peak flapwise bending load derived from the loading above conditions (Class I). The bending load was applied to the flap-wise direction of the wind blade [27]. In order to implement the bending load due to the $70 \mathrm{~m} / \mathrm{s}$ wind, the wind speed needs to be converted into the dynamic pressure $\left(\mathrm{q}_{\mathrm{z}}\right)$. The dynamic pressure of $70 \mathrm{~m} / \mathrm{s}$ gust of wind standard can be calculated with the formula:

$$
\begin{aligned}
& q_{z}=0.613 \cdot x \cdot(V)^{2} \\
& q_{z}=3000 \mathrm{~N} / \mathrm{m}^{2}(\mathrm{~Pa})
\end{aligned}
$$

The theory behind blade design depends mainly on the idea that the wind is perpendicular to the plane of the rotor and moving horizontally over the blade surface [28] since the dynamic pressure in ABAQUS is presented and induced perpendicularly to the surface. Thus, in order to apply the load in a fixed direction, General Surface Traction of loading has been used, Fig. 10.

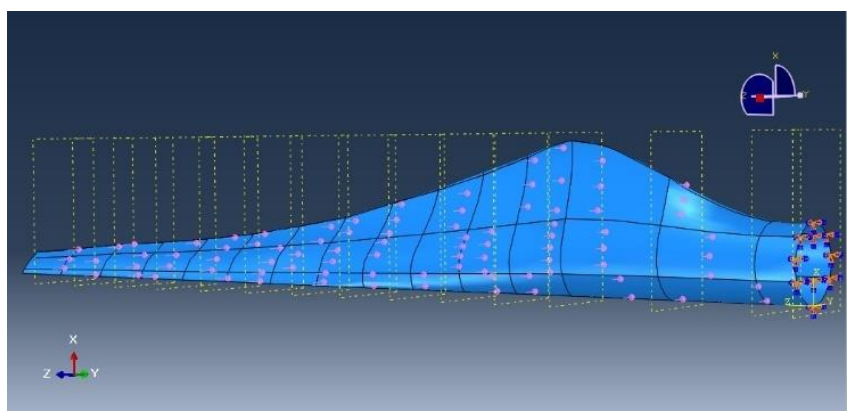

Fig. 10. The application of wind pressure in a fixed direction using the General Surface Traction.

To study the centrifugal loading, a peak tension load derived from the centrifugal movement of the blade was used. In order to define the centrifugal loading in ABAQUS, CENT was used as an option for *DLOAD keyword. Afterward, the square of the rotational speed in radians/sec multiplied by the mass density of the blade was entered. The rotating speed of real $400 \mathrm{~kW}$ wind turbines has been used. According to Vestas V39 wind turbine with a rotor diameter of 39 meters, the average maximum rotating speed is $30 \mathrm{rpm}$. The angular velocity of $30 \mathrm{rpm}$ can be calculated as follows:

$$
\omega=\frac{d \theta}{d t}
$$


$\omega=30 \mathrm{rpm} \times 2 \pi / 60 \mathrm{sec} .=3.14 \mathrm{radians} / \mathrm{sec}$

where $\omega$ is the angular velocity. The angular velocity is further multiplied by the mass density of the blade to produce the centrifugal loading, Fig. 11.

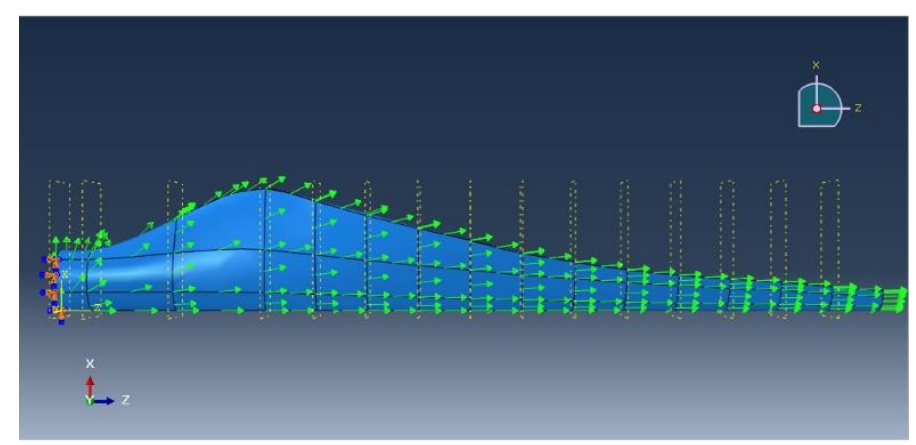

Fig. 11. The implementation of centrifugal loading.

\section{Damage criterion}

The fracture mechanics effect for the entire model was not studied in this work due to its complexity and requirement of massive computational resources [29]. Other methods could be used instead of the approach above under the static analysis. The approach called Hashin failure criterion shows an acceptable and safe performance design for all the blade models. The damage initiation is also based on the fracture mechanics approach using fracture energies of the material and a special damage stabilization scheme to reduce numerical instabilities [30]. Therefore, in this study, the Hashin damage criteria was used to assess the aerodynamic design of the blade.

The Hashin failure criteria take into account four modes of failure, decomposes them into separate fibre and matrix failure modes under tensile and compression stress: Tensile Matrix Mode (HSNMTCRT), Compressive Matrix Mode (HSNMCCRT), Tensile Fibre Mode (HSNFTCRT) and Compressive Fibre Mode (HSNFCCRT) [31]. The Hashin failure criterion has been performed using ABAQUS/CAE and inserting strength parameters for each material are shown in Table 7. These strengths of materials are computed based on the book: "Introduction to composite materials design" [32].

Table 7. The strength parameters of glass and carbon fiber-reinforced nanocomposites.

\begin{tabular}{lccc}
\hline Parameter & GFRP & CFRPN2 & CFRPN5 \\
\hline $\mathrm{F}_{1 \mathrm{t}}(\mathrm{MPa})$ & 1407 & 1749 & 1749 \\
$\mathrm{~F}_{1 \mathrm{c}}(\mathrm{MPa})$ & 980.2 & 1059 & 1063 \\
$\mathrm{~F}_{2 \mathrm{t}}(\mathrm{MPa})$ & 55.34 & 37 & 37.88 \\
$\mathrm{~F}_{2 \mathrm{c}}(\mathrm{MPa})$ & 48.83 & 68.2 & 66.28 \\
$\mathrm{~S}_{5}(\mathrm{MPa})$ & 17.74 & 25.15 & 24.44 \\
$\mathrm{~S}_{6}(\mathrm{MPa})$ & 81.35 & 81.98 & 81.98 \\
\hline
\end{tabular}




\section{Results and discussion}

The static analyses for both flap-wise bending and centrifugal loading of VestasV39 horizontal axis blade are presented. Four models of wind blade were created from different composite materials; the baseline model made of GFRP, and models entirely made of CFRPN2, HGCN2, and HGCN5. The key question regarding the utilization of CFRP toughened with nanoclays in the root area of the wind turbine blade, is whether the nanocomposite can replace a conventional glass fibre reinforced polymer. The two-step analytical homogenization was used to obtain the overall mechanical properties of the four composite model materials. Afterward, the implementation of finite element analysis of four blade models consisting of composite materials was performed. The bending flap-wise is considered to be increasingly critical when the blade reaches its horizontal position as in this case study. Since the mass of the wind turbine blade was ignored, the edgewise bending load was not analyzed [33]. All models were examined under static analysis, flap-wise bending and centrifugal loadings.

\section{Static analysis}

Static analysis under flap-wise bending

Blade models were subjected to a flap-wise bending load that originates from an extreme wind class A. The analysis of the computed results depicts the maximal tip displacement and stress distribution under flap-wise bending load for blade models based on GFRP, CFRPN2, HGCN2, and HGCN5. For more detailed view regarding the Hashin failure criterion, see Appendix B.1, from Figure B.1.1 to Figure B.1.4.

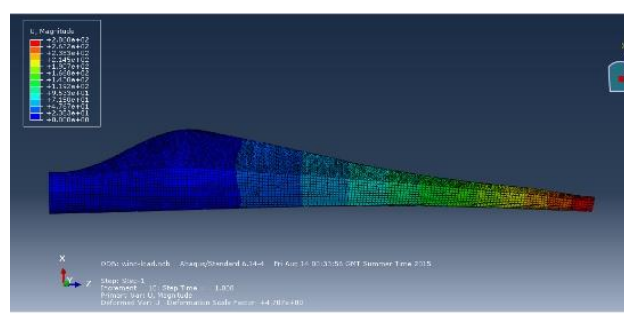

(a)

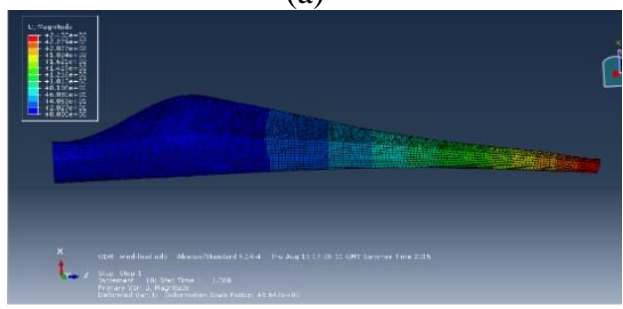

(c)

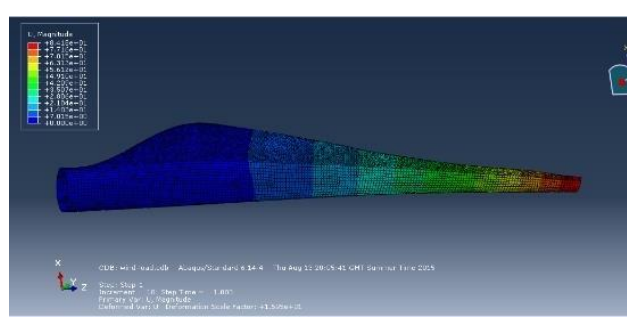

(b)

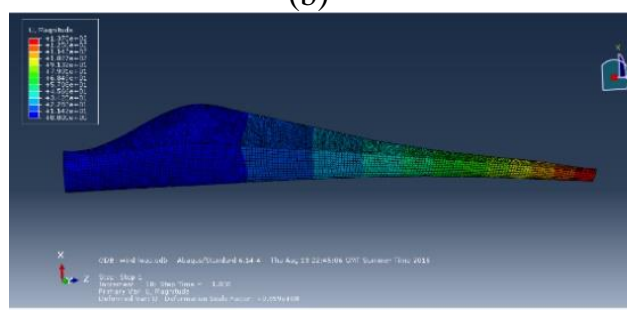

(d)

Fig. 12. The maximum tip displacements under flap-wise bending, they are listed: (a) GFRP with displacement $U 286 \mathrm{~mm}$; (b) CFRPN2 with displacement $U 84.18 \mathrm{~mm}$; (c) HGCN2 with displacement U $243.2 \mathrm{~mm}$; (d) HGCN5 with displacement U $137 \mathrm{~mm}$. 


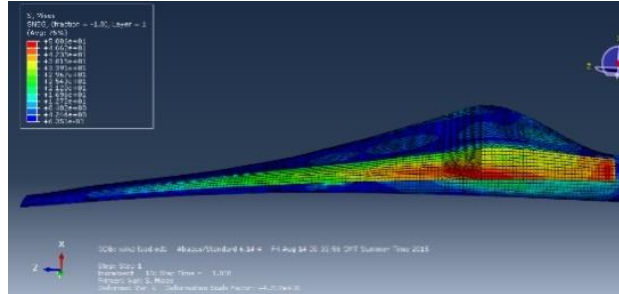

(a)

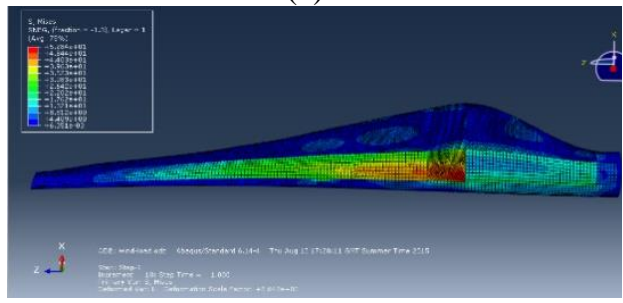

(c)

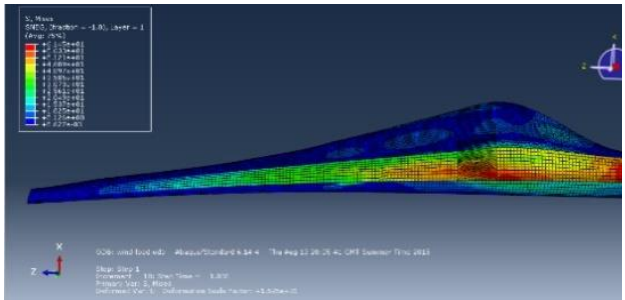

(b)

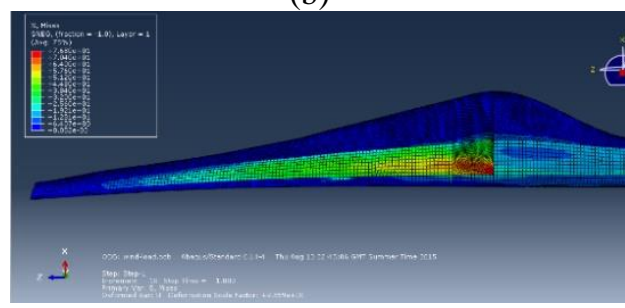

(d)

Fig. 13. The maximum stress distribution under flap-wise bending: (a) GFRP with Max. $S$ Mises $50.86 \mathrm{kN} / \mathrm{m}^{2}$; (b) CFRPN2 with Max. S Mises $61.45 \mathrm{kN} / \mathrm{m}^{2}$; (c) HGCN2 with Max. S Mises $52.84 \mathrm{kN} / \mathrm{m}^{2}$; (d) HGCN5 with Max. S Mises $76.80 \mathrm{kN} / \mathrm{m}^{2}$.

It appears from Figure.12 (a), (b), (c) and (d) that under the flap-wise bending load, the model made CFRPN2 brings about a minimum tip deflection of $84.18 \mathrm{~mm}$, while the baseline blade made of GFRP showed the maximal tip displacement about $(286 \mathrm{~mm})$. By replacing the unidirectional $0^{\circ}$ glass fibres in the center of the layup configuration with HGCN2 and HGCN5 near the root area, the reduction of $243.2 \mathrm{~mm}$ and $137 \mathrm{~mm}$ (14 and 52\%), respectively, in the tip displacements was observed. The modest addition of nanoclay with carbon fibre for the manufacturing of the entire blade leads to a significantly stiffer blade, with a very small deflection, about $70 \%$ lower than that of GFRP composite. Thus, it is reasonable to consider that smaller deflections in the blades may decrease the probability of failure of the whole blade model in the root area as well as the total costs.

The Hashin damage criteria under the static analysis shows an acceptable and safe performance design for all model blades. This damage initiation is based on the fracture mechanics approach using fracture energies of the material and a special damage stabilization scheme to reduce numerical instabilities [30]. From the data in Figure 13 (a), (b), (c) and (d), it is apparent that the maximum stress distribution that occurs at the fixed end, especially in the root areas of the glass model, is reduced in the case of all nanoclay-CFRP models. Regarding the comparison between models of CFRPN2, HGCN2, HGCN5, and the conventional GFRP, HGCN2 model is considered to be safer as it has a lower stress concentration than the others, about $52.84 \mathrm{~N} / \mathrm{m}^{2}$, based on the fact that the minimal tip displacement generates lower stress concentration in the root areas. It may also be the most striking observation that the minimal tip displacement may decrease the probability of crack occurrence and fatigue failure. 
Static analysis under centrifugal loading

The blade models were subjected to a centrifugal load case that results from angular velocity. The analysis of the computed results depicts the maximal tip displacement and stress distribution under centrifugal loading for blade models based on GFRP, CFRPN2, HGCN2, and HGCN5. For a more detailed view regarding the Hashin failure criteria, see Appendix B.2, from Figure B.2.1 to Figure B.2.4.

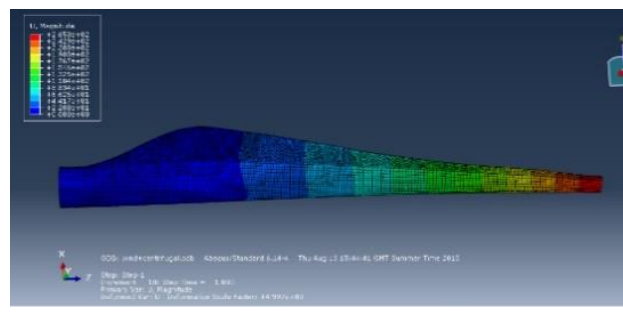

(a)

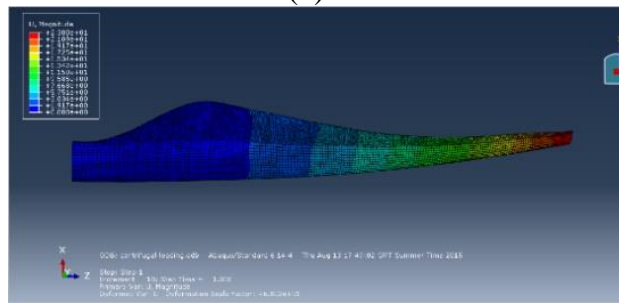

(c)

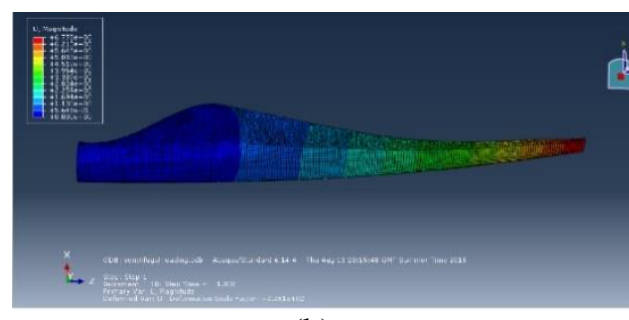

(b)

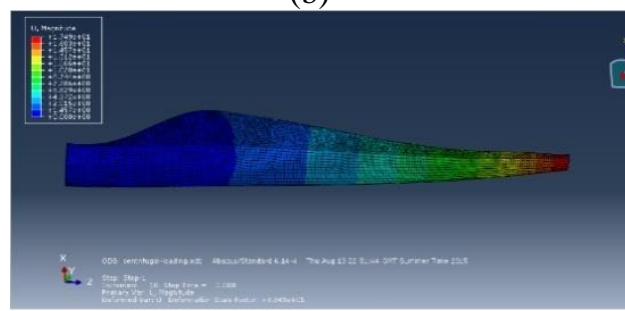

(d)

Fig. 14. The maximal tip displacements under centrifugal loading: (a) GFRP with displacement U $265 \mathrm{~mm}$; (b) CFRPN2 with displacement U $6.778 \mathrm{~mm}$; (c) HGCN2 with displacement $U 23 \mathrm{~mm}$; (d) HGCN5 with displacement $U 17.49 \mathrm{~mm}$.

Under centrifugal loading, there is clearly a similar trend as for the analysis under flap-wise bending, but differing in the magnitude, see Figure.14 (a), (b), (c) and (d) and Figure.16 (a), (b), (c) and (d). The CFRP2 model brings about a minimal tip deflection, about $6.778 \mathrm{~mm}$, while the baseline blade made of GFRP showed a maximal tip displacement, about $(265 \mathrm{~mm})$. By replacing the unidirectional $0^{\circ}$ glass fibres in the center of the layup configuration with CFRPN2 and CFRPN5 near the root area, the reduction in the tip displacement of 23 and $17.49 \mathrm{~mm}$ (91\% and 97\%), respectively, was observed.

Regarding displacement, stress distribution and the Hashin damage criteria, both HGCN2 and HGCN5 models lead to a significantly stiffer blade, with reasonably small deflections, about 15 and $50 \%$ less than the conventional one made of glass, respectively. In comparison, to the displacements under the flap-wise bending with the aforementioned centrifugal findings, one can observe that centrifugal loading can be ignored due to its small magnitudes. Also, the Hashin damage criteria under the centrifugal loading are ten times safer than the flap-wise bending damage criteria. This indicates the importance of optimization of flap-wise bending in the blade performance design. 


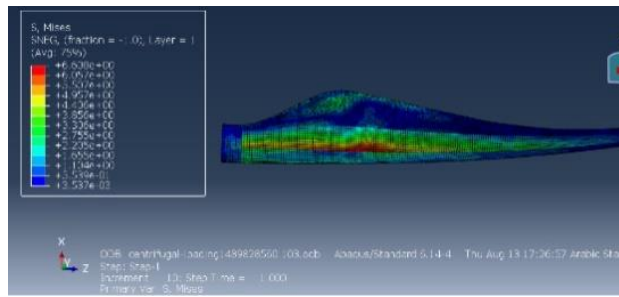

(a)

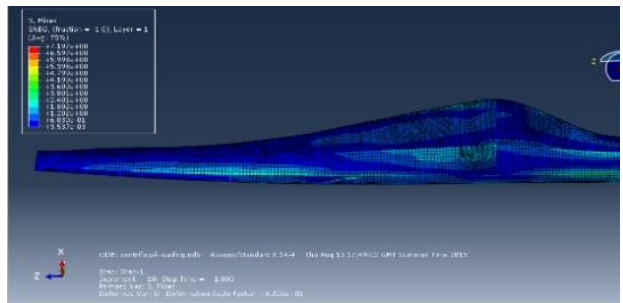

(c)

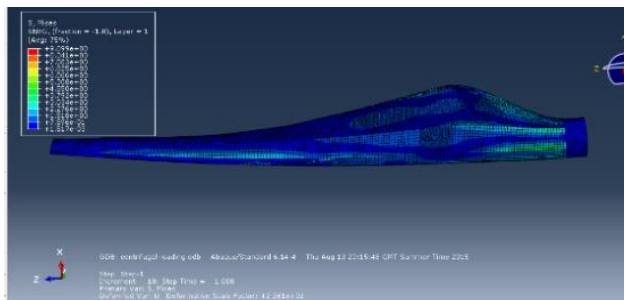

(b)

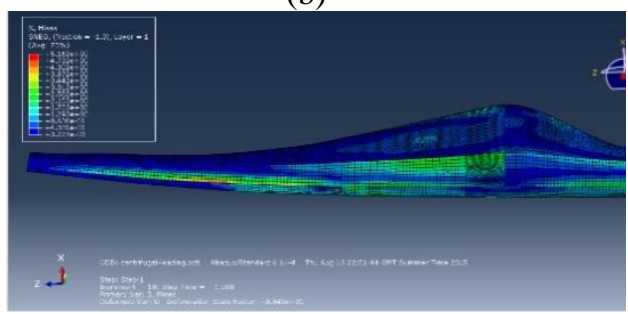

(d)

Fig. 15. The maximal stress distribution under centrifugal loading, they are listed: (a) GFRP with Max. S Mises $6.608 \mathrm{kN} / \mathrm{m}^{2}$; (b)CFRPN2 with Max. S Mises $9.099 \mathrm{kN} / \mathrm{m}^{2}$; (c)HGCN2 with Max. S Mises $7.197 \mathrm{kN} / \mathrm{m}^{2}$;

(d) HGCN5 with Max. S Mises $5.162 \mathrm{kN} / \mathrm{m}^{2}$.

\section{Conclusion}

The present study was designed to determine the efficient utilization of nanoclay added to carbon fibre reinforced polymer in the joining zone between the root and the blade. The most apparent finding to emerge from this study is that the modest addition of nanoclay $(2 \%)$ with carbon fibre reinforced polymer for the manufacturing of the entire wind blade leads to a significantly stiffer blade, with a very small deflection, about $70 \%$ less than that of glass-fiber reinforced composite. Among the investigated models, HGCN2 model is considered to be safer as it has a lower stress concentration than others about $\left(52.84 \mathrm{KN} / \mathrm{m}^{2}\right)$. A reasonable considering is that smaller deflections in the blades may decrease the probability of failure for whole blade model in the root area as well as decrease the total costs. Therefore, it can be discussed that HGCN2 and HGCN5 blade models may suffer fewer cracks due to their greater stiffness. This study has implications for both manufacturers and researchers. The findings contribute to decisions related to material selection and structural design when it comes to the construction of wind turbine blades.

Further research should be undertaken in the following areas: an experimental investigation to estimate the strength of nanoclay/carbon fibre reinforced polymer and compare with the present study. Theoretical investigation of the effects of intercalation and exfoliation on the analytical homogenization by using Guth and Gold approach which considered the interaction between filler particles, and study of the performance of hybrid blade designs in larger scale wind turbine blades. Further research is also needed in order to examine different hybrid configurations such as diverse layup sequences or even different ply orientations. Finally, a more appropriate blade design 
based on the sandwich concept design could be developed followed by an in-depth buckling analysis.

\section{Acknowledgments}

The manuscript is based on M.Sc. thesis by the authors and gratefully acknowledge the financial support of The Higher Committee for Education Development in Iraq (HCED).

\section{References}

[1] M. M. Shokrieh, R. Rafiee: Composite Structures, 74 (2006) 332-342.

[2] P.-C. Ma, Y Zhang: Renewable Sustainable Energy Rev, 30 (2014) 651-660.

[3] F. C. Campbell, 2010. Structural composite materials. ASM international.

[4] H. C. Lin: Appl Mech Mater, 87 Trans Tech Publ (2011) 49-54.

[5] J. Cuppoletti: Nanocomposites and polymers with analytical methods, InTechOpen, 2011.

[6] N. Saba, P. M. Tahir, M. Jawaid: Polymers, 6 (2014) 2247- 2273.

[7] C. Chen, T. Kam: Procedia Eng, 14 (2011) 1973-1981.

[8] E. S. Kim, J. H. Shim, J. Y. Woo, K. S. Yoo, J. S. Yoon: J Appl Polym Sci, 117 (2010) 809-816.

[9] Y. Xu, S. Van Hoa: Compos Sci Technol, 68 (2008) 854-861.

[10] N. A. Siddiqui, R. S. Woo, J.-K. Kim, C. C. Leung, A. Munir: Composites Part A, 38 (2007) 449-460.

[11] J. J. Karippal, H. Narasimha Murthy, K. Rai, M. Sreejith, M. Krishna: J Compos Mater, 45 (2011) 1893-1899.

[12]S. Kurukuri, S. Eckardt: A review of homogenization techniques for heterogeneous materials, Term paper. Advanced Mechanics of Materials and Structures, Graduate School in Structural Engineering, Germany, 2004.

[13] G. Dai, L. Mishnaevsky Jr: Compos Sci Technol, 91 (2014) 71-81.

[14]G. Dai, L. Mishnaevsky Jr: Compos Sci Technol, 94 (2014) 71-79.

[15] MatWeb. 2015. BYK Cloisite ${ }^{\circledR} \mathrm{Na}+$ Nanoclay, http://www.matweb.com/ search/datasheet_print.aspx?matguid=5f1c2fe7b6554bf59b2dee490b3971e2 , Accessed 10.12.2018.

[16] Y. Benveniste: Mech Mater, 6 (1987) 147-157.

[17] J. Tangier, D. Somers: NREL airfoil familieses for HAWTs, In: American Wind Energy Association Windpower Conference, Washington, DC, (National Renewable Energy Laboratory) NREL. TP-442-7109, 1995.

[18] K. Cox, A. Echtermeyer: Energy Procedia, 24 (2012) 194-201.

[19] L. Mishnaevsky Jr: Composite materials in wind energy technology. Thermal to Mechanical Energy Conversion: Engines and Requirements, EOLSS Publishers: Oxford, UK, 2011.

[20] A. Mukherjee, B. Varughese: Composites Part B, 32 (2001) 153-164.

[21]E. M. Lenoe: Fibrous composites in structural design, Springer Science \& Business Media, 2012.

[22] K. Vallons, G. Adolphs, P. Lucas, S. V. Lomov, I. Verpoest: Mech Ind, 14 (2013) 175-189.

[23] C. Dong, I. J. Davies: Mater Des, 37 (2012) 450-457.

[24] L. R. McKittrick, D. S. Cairns, J. Mandell, D. C. Combs, D. A. Rabern, R. D. Van Luchene: Analysis of a composite blade design for the aoc 15/50 wind 
turbine using a finite element model, Sandia National Laboratories Report SAND2001-1441, 2001.

[25]E. Hau, H. von Renouard: Wind turbines: fundamentals, technologies, application, economics. Springer, 2003.

[26] I. E. Commission, IEC 61400-1: Wind turbine generator systems-part 1: Safety requirements. International Standard, 1400-1, 1999.

[27]D. A. Griffin: Windpact turbine design scaling studies technical area 1composite blades for 80-to 120-meter rotor. National Renewable Energy Laboratory, Colorado, USA, Tech. Rep. NREL/SR-500-29492, 2001.

[28] K. Grogg: Harvesting the wind: the physics of wind turbines. Physics and Astronomy Comps Papers, 7, 2005.

[29] P. Brøndsted, R. P. Nijssen: Advances in wind turbine blade design and materials, Elsevier, 2013.

[30] A. Rahai, M. Alipoura: Procedia Eng 14 (2011) 3205-3212.

[31]R. M. Christensen: Mechanics of composite materials, Dover Publications, 2012.

[32] . J. Barbero: Introduction to composite materials design, CRC press, 2017.

[33] M. Adaramola: Wind Turbine Technology: Principles and Design, Apple Academic Press, 2014.

\section{Appendix A}

Appendix A. Layup Schedule

Table A.1. Layup Schedule for GFRP and CFRPN2 models.

\begin{tabular}{lccc}
\hline Component & $\begin{array}{c}\text { Location } \\
(\mathrm{m})\end{array}$ & Layup Schedule & $\begin{array}{c}\text { Thickness } \\
(\mathrm{mm})\end{array}$ \\
\hline Root & 0 to 0.5 & {$[((0 / 45 / 90 /-45) 4) / 0] 2 \mathrm{~s}$} & 34 \\
Spar Cap & 0 to 0.5 & {$[((0 / 45 / 90 /-45) 4) / 0] 2 \mathrm{~s}$} & 34 \\
& 0.5 to 3.2 & {$[((0 / 45 / 90 /-45 / 0 / 45 / 90) 2) / 0] 2 \mathrm{~s}$} & 30 \\
& 3.2 to 5.6 & {$[((0 / 45 / 90 /-45 / 0 / 45) 2) / 0] 2 \mathrm{~s}$} & 26 \\
& 5.6 to 8.0 & {$[((0 / 45 / 90 /-45 / 0) 2) / 0] 2 \mathrm{~s}$} & 22 \\
& 8.0 to 10.4 & {$[((0 / 45 / 90 /-45) 2) / 0] 2 \mathrm{~s}$} & 18 \\
Leading & 10.4 to 12.8 & {$[(0 / 45 /-45 / 0 / 45 /-45 / 0] 2 \mathrm{~s}$} & 14 \\
Edge & 0.5 to 4.0 & {$[(0 / 45 /-45 / 0 / 45 /-45 / 0] 2 \mathrm{~s}$} & 12 \\
& 4.0 to 8.8 & {$[(0 / 45 /-45 / 0 / 45 / 0 / 0 / 45 / 0 / 45 /-45 / 0] \mathrm{s}$} & 10 \\
Trailing & 8.8 to 12.8 & {$[(0 / 45 /-45 / 0 / 0 / 0 / 0 / 45 /-45 / 0] \mathrm{s}$} & 11 \\
Edge & 0.5 to 9.6 & {$[(0 / 45 /-45 / 0 / 0 / 0 / 45 / 0 / 45 /-45 / 0] \mathrm{s}$} & \\
& & &
\end{tabular}




\begin{tabular}{lccc} 
& 9.6 to 12.8 & {$[(0 / 45 /-45 / 0 / 45] \mathrm{s}$} & 5 \\
Spar Webs & 0 to 12.8 & {$[(0 / 45 /-45 / 0 / 45 / 0 / 0 / 45 / 0 / 45 /-45 / 0] \mathrm{s}$} & 12 \\
Spar Flange & 0.5 to 12.8 & {$[(0 / 45 /-45 / 0 / 45 / 0 / 0 / 45 / 0 / 45 /-45 / 0] \mathrm{s}$} & 12 \\
\hline
\end{tabular}

Table A.2. Layup Schedule for HGCN2 and HGCN5 models.

\begin{tabular}{|c|c|c|c|}
\hline Component & $\begin{array}{c}\text { Location } \\
\text { (m) }\end{array}$ & Layup Schedule & $\begin{array}{l}\text { Thickne } \\
\text { ss (mm) }\end{array}$ \\
\hline Root & 0 to 0.5 & {$[((0 \mathrm{~g} / 45 \mathrm{~g} / 90 \mathrm{~g} /-45 \mathrm{~g}) 4) / 0 \mathrm{~g}] 2 \mathrm{~s}$} & 34 \\
\hline \multirow[t]{5}{*}{ Spar Cap } & 0.5 to 3.2 & {$[((0 \mathrm{~g} / 45 \mathrm{~g} / 90 \mathrm{~g} /-45 \mathrm{~g} / 0 \mathrm{C} / 45 \mathrm{~g} / 90 \mathrm{~g}) 2) / 0 \mathrm{~g}] 2 \mathrm{~s}$} & 30 \\
\hline & 3.2 to 5.6 & $*[((0 \mathrm{~g} / 45 \mathrm{~g} / 90 \mathrm{~g} /-45 \mathrm{~g} / 0 \mathrm{C} / 45 \mathrm{~g}) 2) / 0 \mathrm{~g}] 2 \mathrm{~s}$ & 26 \\
\hline & 5.6 to 8.0 & {$[((0 \mathrm{~g} / 45 \mathrm{~g} / 90 \mathrm{~g} /-45 \mathrm{~g} / 0 \mathrm{~g}) 2) / 0 \mathrm{~g}] 2 \mathrm{~s}$} & 22 \\
\hline & 8.0 to 10.4 & {$[((0 \mathrm{~g} / 45 \mathrm{~g} / 90 \mathrm{~g} /-45 \mathrm{~g}) 2) / 0 \mathrm{~g}] 2 \mathrm{~s}$} & 18 \\
\hline & 10.4 to 12.8 & {$[(0 \mathrm{~g} / 45 \mathrm{~g} /-45 \mathrm{~g} / 0 \mathrm{~g} / 45 \mathrm{~g} /-45 \mathrm{~g} / 0 \mathrm{~g}] 2 \mathrm{~s}$} & 14 \\
\hline Leading & 0.5 to 4.0 & {$[(0 \mathrm{~g} / 45 \mathrm{~g} /-45 \mathrm{~g} / 0 \mathrm{~g} / 45 \mathrm{~g} /-45 \mathrm{~g} / 0 \mathrm{~g}] 2 \mathrm{~s}$} & 14 \\
\hline \multicolumn{4}{|l|}{ Edge } \\
\hline & 4.0 to 8.8 & {$[(0 \mathrm{~g} / 45 \mathrm{~g} /-45 \mathrm{~g} / 0 \mathrm{~g} / 45 \mathrm{~g} / 0 \mathrm{~g} / 0 \mathrm{~g} / 45 \mathrm{~g} / 0 \mathrm{~g} / 45 \mathrm{~g} /-45 \mathrm{~g} / 0 \mathrm{~g}] \mathrm{s}$} & 12 \\
\hline & 8.8 to 12.8 & {$[(0 \mathrm{~g} / 45 \mathrm{~g} /-45 \mathrm{~g} / 0 \mathrm{~g} / 0 \mathrm{~g} / 0 \mathrm{~g} / 0 \mathrm{~g} / 45 \mathrm{~g} /-45 \mathrm{~g} / 0 \mathrm{~g}] \mathrm{s}$} & 10 \\
\hline Trailing & 0.5 to 3.2 & {$[(0 \mathrm{~g} / 45 \mathrm{~g} /-45 \mathrm{~g} / 0 \mathrm{C} / 0 \mathrm{C} / 0 \mathrm{C} / 45 \mathrm{~g} / 0 \mathrm{C} / 45 \mathrm{~g} /-45 \mathrm{~g} / 0 \mathrm{~g}] \mathrm{s}$} & 11 \\
\hline \multicolumn{4}{|l|}{ Edge } \\
\hline & 3.2 to 9.6 & {$[(0 \mathrm{~g} / 45 \mathrm{~g} /-45 \mathrm{~g} / 0 \mathrm{~g} / 0 \mathrm{~g} / 0 \mathrm{~g} / 45 \mathrm{~g} / 0 \mathrm{~g} / 45 \mathrm{~g} /-45 \mathrm{~g} / 0 \mathrm{~g}] \mathrm{s}$} & 11 \\
\hline & 9.6 to 12.8 & {$[(0 \mathrm{~g} / 45 \mathrm{~g} /-45 \mathrm{~g} / 0 \mathrm{~g} / 45 \mathrm{~g}] \mathrm{s}$} & 5 \\
\hline Spar Webs & 0 to 12.8 & {$[(0 \mathrm{~g} / 45 \mathrm{~g} /-45 \mathrm{~g} / 0 \mathrm{~g} / 45 \mathrm{~g} / 0 \mathrm{~g} / 0 \mathrm{~g} / 45 \mathrm{~g} / 0 \mathrm{~g} / 45 \mathrm{~g} /-45 \mathrm{~g} / 0 \mathrm{~g}] \mathrm{s}$} & 12 \\
\hline \multirow[t]{2}{*}{ Spar Flange } & 0.5 to 3.2 & {$[(0 \mathrm{~g} / 45 \mathrm{~g} /-45 \mathrm{~g} / 0 \mathrm{C} / 45 \mathrm{~g} / 0 \mathrm{C} / 0 \mathrm{C} / 45 \mathrm{~g} / 0 \mathrm{C} / 45 \mathrm{~g} /-45 \mathrm{~g} / 0 \mathrm{~g}] \mathrm{s}$} & 12 \\
\hline & 3.2 to 12.8 & {$[(0 \mathrm{~g} / 45 \mathrm{~g} /-45 \mathrm{~g} / 0 \mathrm{~g} / 45 \mathrm{~g} / 0 \mathrm{~g} / 0 \mathrm{~g} / 45 \mathrm{~g} / 0 \mathrm{~g} / 45 \mathrm{~g} /-45 \mathrm{~g} / 0 \mathrm{~g}] \mathrm{s}$} & 12 \\
\hline
\end{tabular}

* This Layup configuration indicates an extra layup reinforced for HGCN5. 


\section{Appendix B}

Appendix B.1. Hashin Damage Criterion under Flap-wise Bending

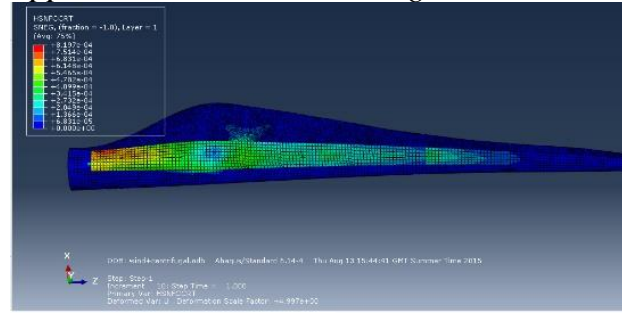

(a)

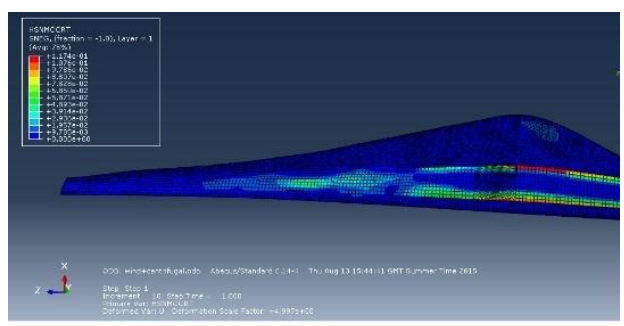

(c)

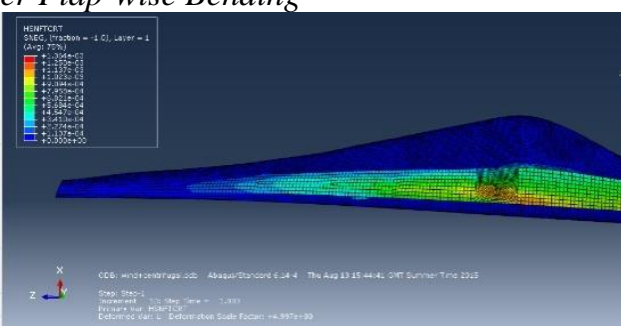

(b)

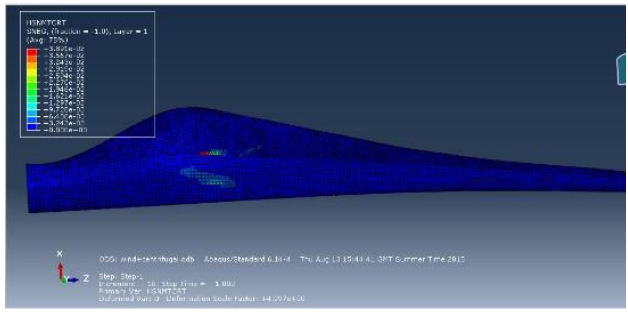

(d)

Fig. B.1.1. Hashin Damage Criterion for GFRP under Flap-wise Bending, they are listed: (a)HSNFCCRT with $8.197 \times 10^{-4}$; (b) HSNFTCRT with $1.364 \times 10^{-3}$; (c) HSNMCCRT with $1.174 \times 10^{-1}$; (d) HSNMTCRT with $3.891 \times 10^{-2}$.

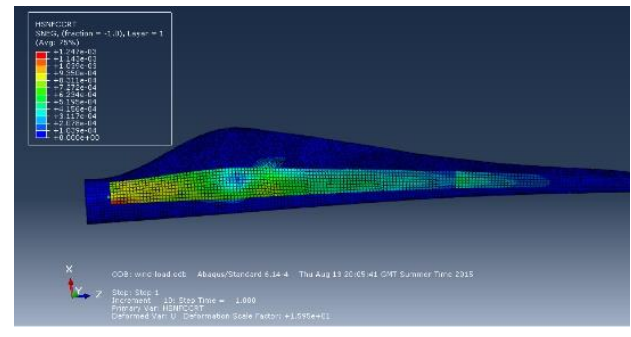

(a)

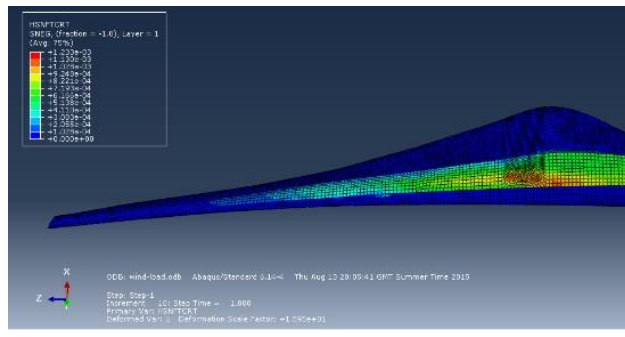

(b) 


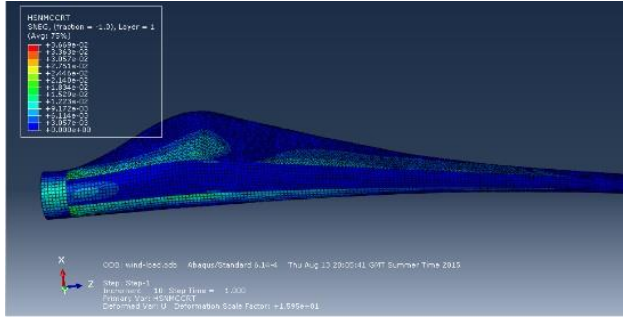

(c)

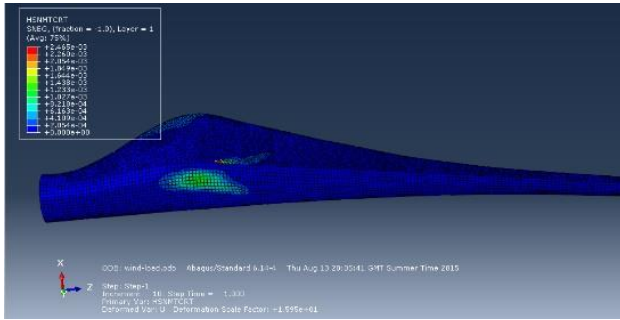

(d)

Fig. B.1.2. Hashin Damage Criterion for CFRPN2 under Flap-wise Bending, they are listed as: (a) HSNFCCRT with $1.247 \times 10^{-3}$; (b) HSNFTCRT with $1.233 \times 10^{-3}$;

(c) HSNMCCRT with $3.669 \times 10^{-2}$; (d) HSNMTCRT with $2.465 \times 10^{-3}$

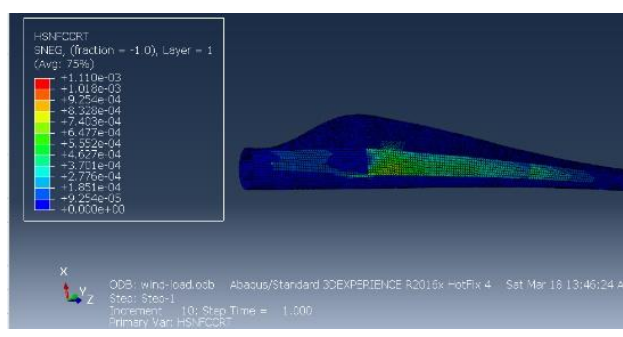

(a)

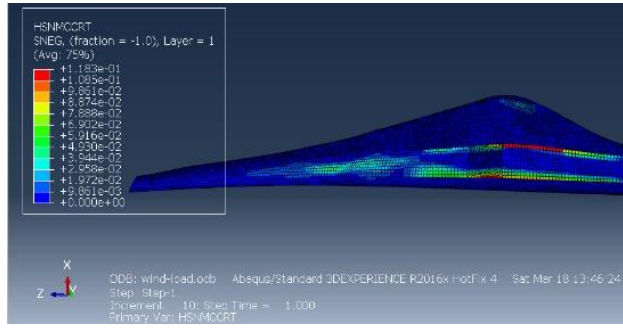

(c)

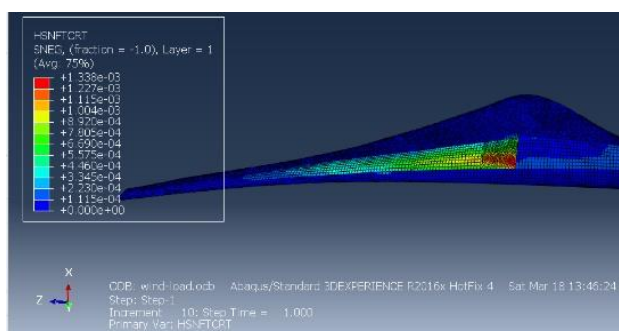

(b)

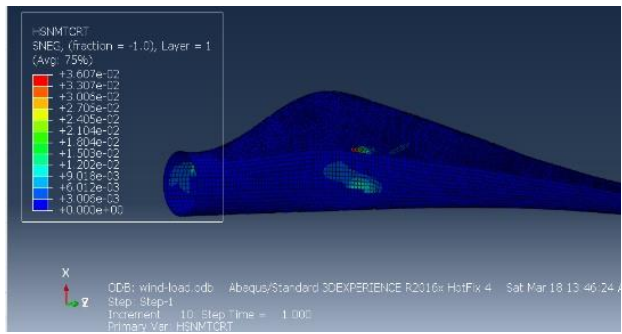

(d)

Fig. B.1.3. Hashin Damage Criterion for HGCN2 under Flap-wise Bending, they are listed as: (a) HSNFCCRT with $1.110 \times 10^{-3}$; (b) HSNFTCRT with $1.338 \times 10^{-3}$; (c) HSNMCCRT with $1.183 \times 10^{-2}$; (d) HSNMTCRT with $3.607 \times 10^{-2}$. 


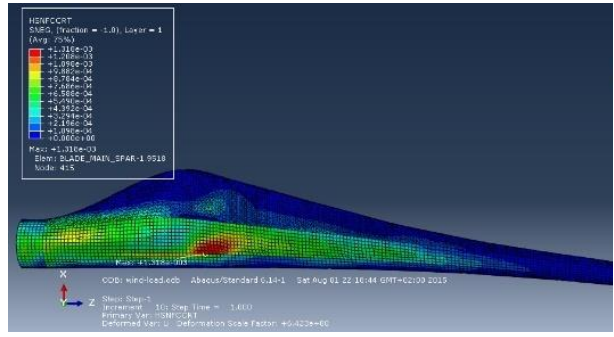

(a)

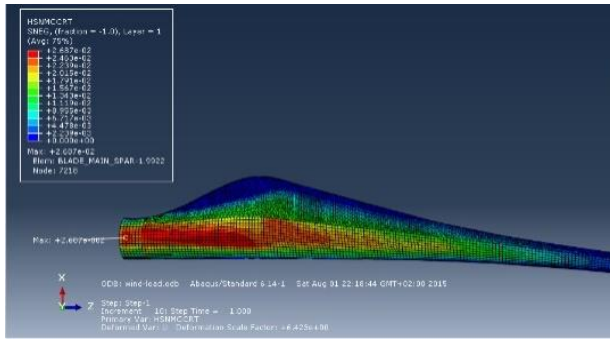

(c)

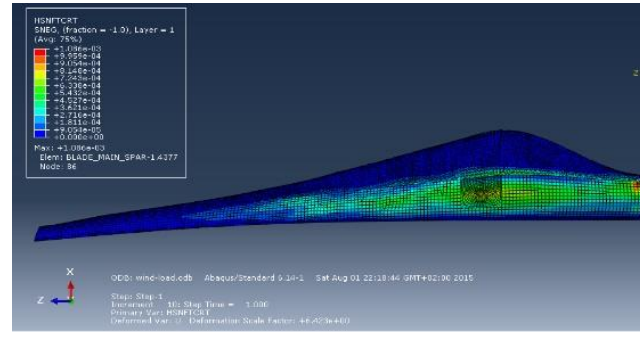

(b)

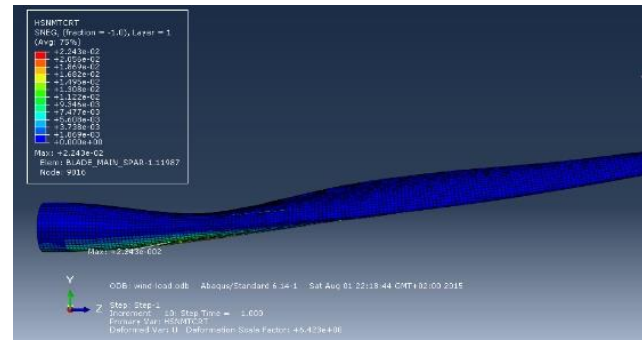

(d)

Fig. B.1.4: Hashin Damage Criterion for HGCN5 under Flap-wise Bending, they are listed as: (a) HSNFCCRT with $1.318 \times 10-3$; (b) HSNFTCRT with $1.086 \times 10^{-3}$; (c) HSNMCCRT with $2.687 \times 10^{-2}$; (d) HSNMTCRT with $2.243 \times 10^{-2}$.

\section{Appendix B.2. Hashin Damage Criterion Under Centrifugal Loading}

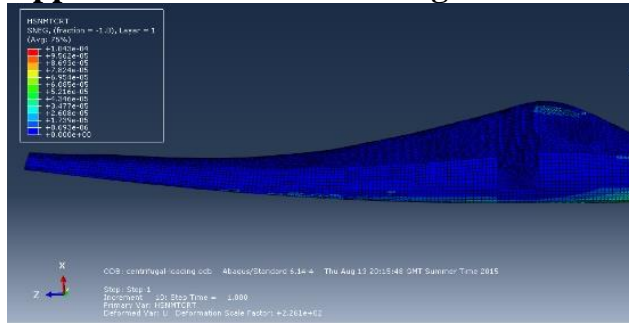

(a)

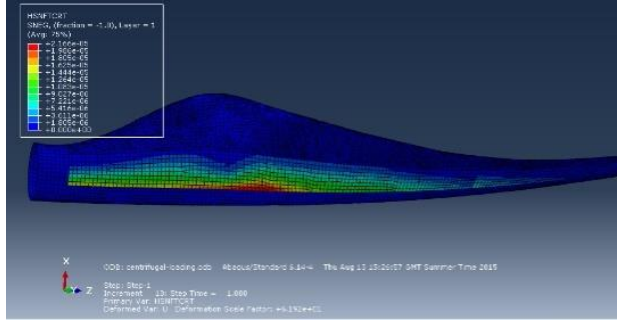

(b) 


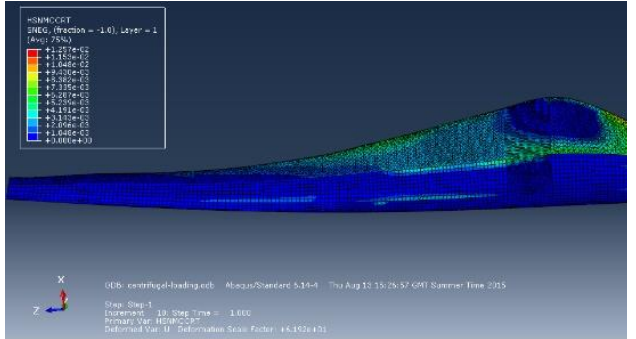

(c)

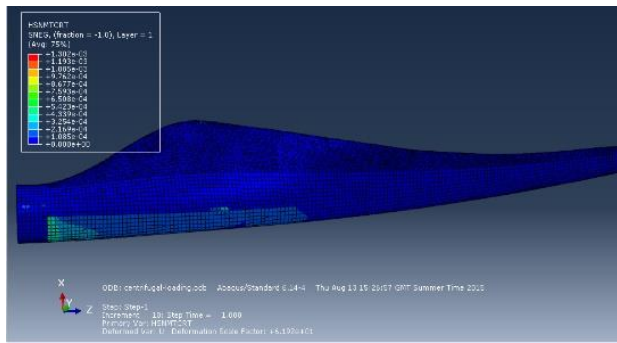

(d)

Fig. B.2.1. Hashin Damage Criterion for GFRP under Centrifugal Loading, they are listed as: (a) HSNFCCRT with $1.043 \times 10^{-4}$; (b) HSNFTCRT with $2.166 \times 10^{-5}$; (c) HSNMCCRT with $1.257 \times 10^{-2}$; (d) HSNMTCRT with $1.302 \times 10^{-3}$.

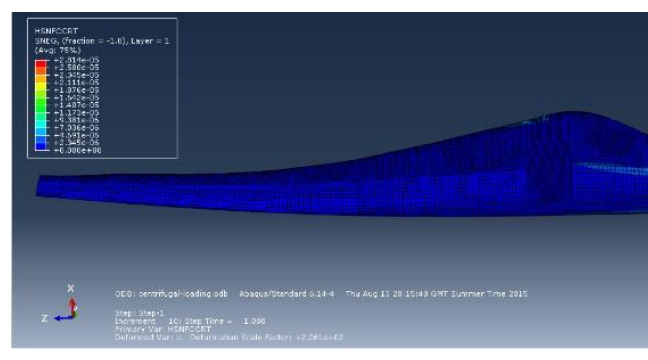

(a)

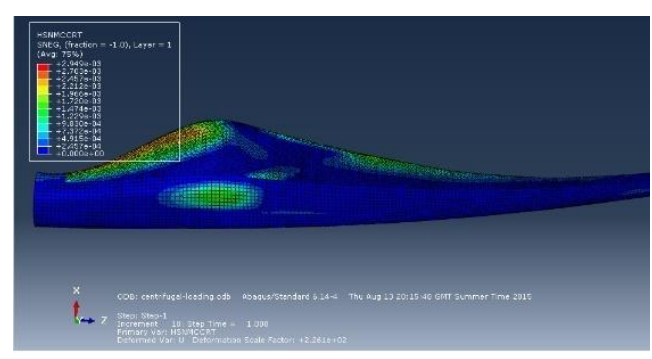

(c)

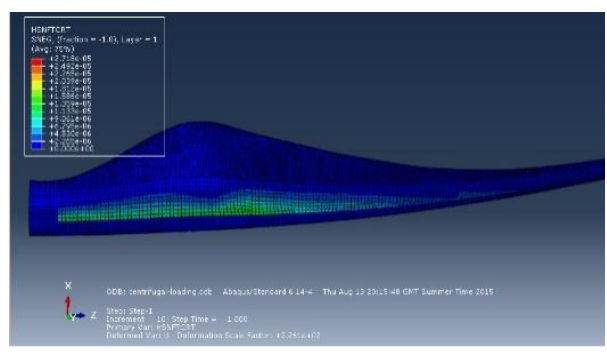

(b)

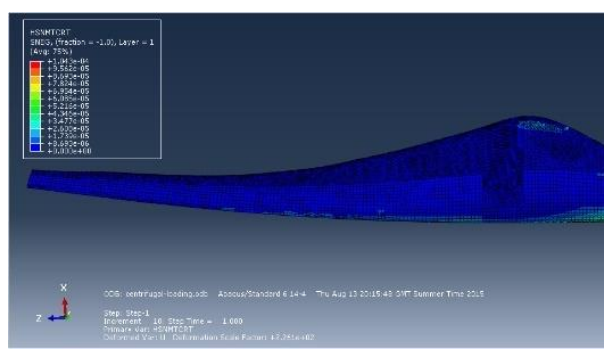

(d)

Fig. B.2.2. Hashin Damage Criterion for CFRPN2 under Centrifugal Loading, they are listed as: (a) HSNFCCRT with $2.814 \times 10^{-5}$; (b) HSNFTCRT with $2.718 \times 10^{-5}$; (c) HSNMCCRT with $2.949 \times 10^{-3}$; (d) HSNMTCRT with $1.043 \times 10^{-4}$. 


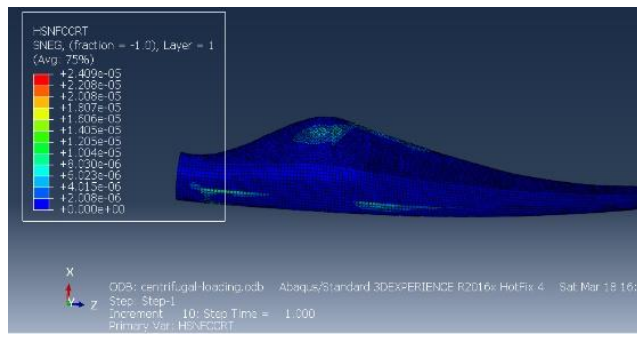

(a)

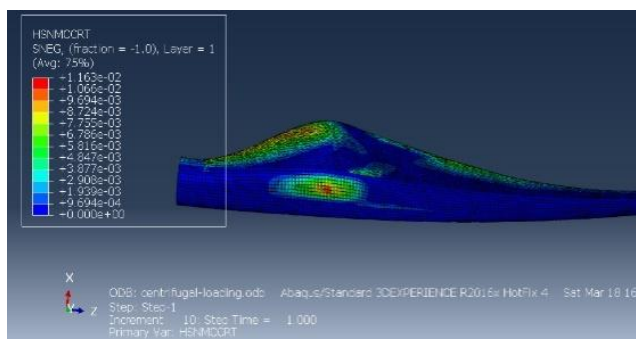

(c)

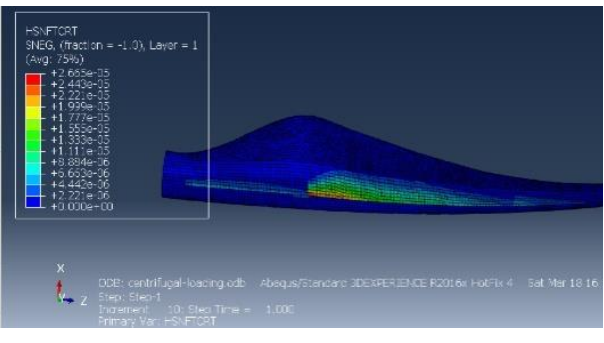

(b)

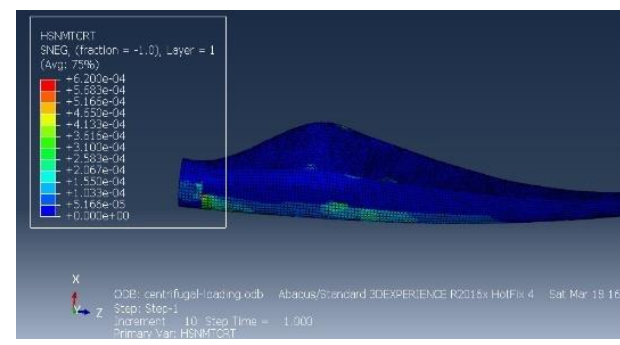

(d)

Fig. B.2.3. Hashin Damage Criterion for HGCN2 under Centrifugal Loading, they are listed as: (a) HSNFCCRT with $2.409 \times 10^{-5}$; (b) HSNFTCRT with $2.665 \times 10^{-5}$; (c) HSNMCCRT with $1.163 \times 10^{-2}$; (d) HSNMTCRT with $6.2 \times 10^{-4}$.

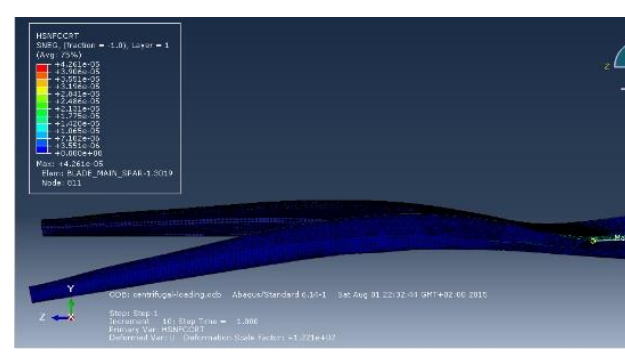

(a)

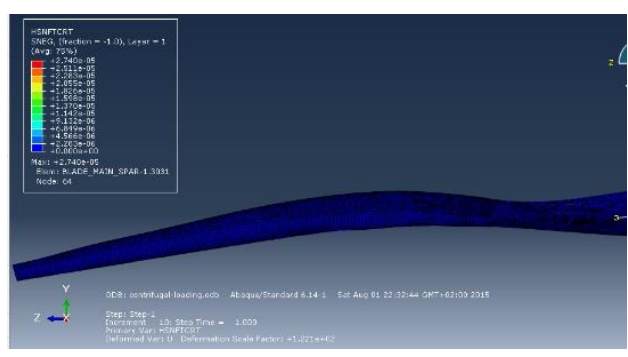

(b) 


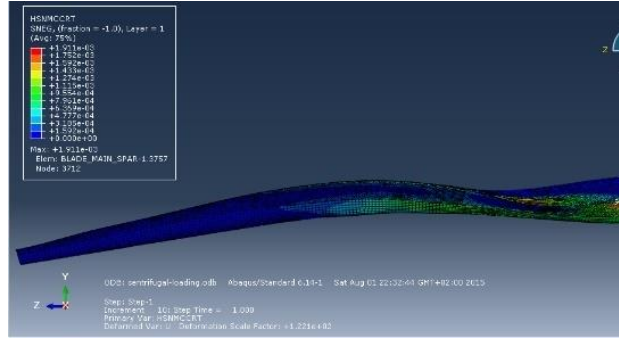

(c)

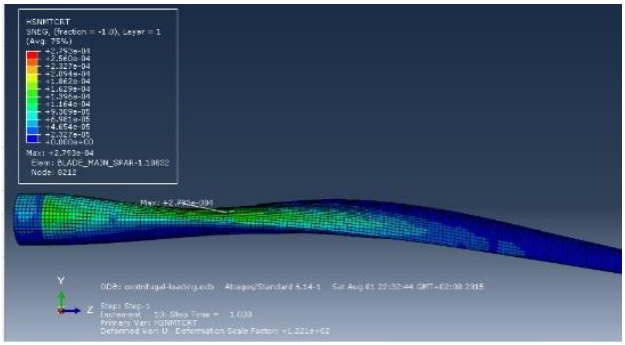

(d)

Fig. B.2.4. Hashin Damage Criterion for HGCN5 under Centrifugal Loading, they are listed as: (a) HSNFCCRT with $4.261 \times 10^{-5}$; (b) HSNFTCRT with $2.470 \times 10^{-5}$; (c) HSNMCCRT with $1.911 \times 10^{-3}$; (d) HSNMTCRT with $2.793 \times 10^{-4}$.

\section{(c) (i) Creative Commons License}

This work is licensed under a Creative Commons Attribution 4.0 International License. 